\title{
The effect of the addition of Alumina powder on the confinement properties of a cement mortar
}

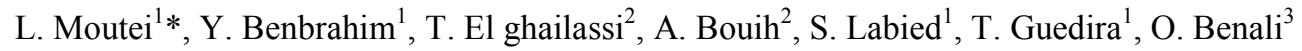 \\ 1Laboratoires des matériaux, Electrochimie et environnement, Faculté des sciences, Université Ibn Tofail, BP 133, \\ 14000 Kenitra, Maroc. \\ 2Unité de gestion des déchets radioactifs, Centre National De L'énergie, Des Sciences Et Techniques Nucléaires \\ (CNESTEN) PB 1382, 10001 Kenitra, Maroc. \\ 3Laboratoire des procédés de séparation, Faculté des Sciences, Université Ibn Tofail, BP 133, 14000 Kenitra, \\ Maroc.
}

\begin{abstract}
Organic radioactive waste can occur in solid, liquid or rarely gaseous form. In general, organic components of radioactive waste Generally, the organic components of the radioactive waste have a contaminant effect stronger than most of the inorganic components, because of their low melting point, of their answer to the radiolyse or of their volatilitydu to their low melting point, to their answer to the radiolyse or to their volatility. This property can significantly affect the strategy adopted for their management. Organic radioactive waste results from the use of radioisotopes in the National Center for Energy, Nuclear Science and Technology (CNESTEN) and from medical applications. Organic radioactive waste requires management steps that take into account not only their radioactivity but also their chemical content. The aim of this study is the optimization of the stabilization of radioactive organic effluents in cementitious matrices. Thus, we study the effects of the addition of the alumina powder on the physicochemical and mechanical properties of the cement paste. The mortar was made by mixing Portland cement, sand, water and alumina powder $(88 \mu \mathrm{m})$. The study showed that the addition of $12 \%$ alumina powder improves the compressive strength.
\end{abstract}

Mots-clés:cement Matrix, alumina powder, compressive strength.

\section{INTRODUCTION}

The radioactive material is used in scientific studies, medical and industrial applications and in agriculture. However, the use of natural and artificial radioactivities leads to waste, among which many contain important levels of radionucléide. The management approach of the waste radioactive is different from that of the other types of waste [1].The radioactive waste has very different physical natures requiring a special treatmentand a longterm storage. The radioactive organic effluents are mainly producted from the exploitation and the maintenance of research laboratories and from the installations of the nuclear Research center of Maâmoura( CENM) [ 2 ]. The volume of the organic effluents generated is low Compared with the other radioactive waste; nevertheless, they require anadequate strategy of management for the treatment and the immobilization, which aims at reducing the potential of migration or dispersal of contaminants, including radionucléides. The International Atomic Energy Agency (IAEA) defines the immobilization of waste by the solidification like the conversion of a waste. It facilitates the handling, the transport, the storage and the elimination of the organic radioactive effluents [3-4].However, contaminated waste by organic molecules as oil, cannot be well treated. The addition of organic oil in a cement-based matrix affects negatively its mechanical properties and more exactly its compressive strength[5] this paper presents a preliminary study to improve the physico-chemical and mechanical properties by realizing acementitious matrix of which the main properties arethe conversion of the liquid radioactive organic waste in a compatible organic solid shape with the cementation to facilitate the long-term conditioning. The mortar as the cementitious material has a low resistance and a limited durability; that's why the improvement of the mechanical properties is necessary to increase its performance as packaging material of the radioactive waste. To surmount these inconveniences, particles are added as fillers incementitious matrix to improve their physico-chemical and mechanics properties. Various studies showed that the use of diverse materials such as $\mathrm{SiO} 2, \mathrm{Fe} 2 \mathrm{O} 3, \mathrm{Fe} 3 \mathrm{O} 4$, fibers and clays [6-7] improve the compression resistance and in the flexion in the 7 th day and in the 28th day the mortars, furthermore, the addition of these particles increases the durability and several other properties.

In this experimental study, the main objective is to study the effect of the addition of the alumina powder on the 
physico-chemical and mechanical properties of the mortar.

\section{MATÉRIALS AND METHODS}

In this work, the influences of Alumina powder $\left(\mathrm{Al}_{2} \mathrm{O}_{3}\right)$ on compressive strength of cement matrix have been investigated. The reason for using $\mathrm{Al}_{2} \mathrm{O}_{3}$ as a partial adds to the cement fraction. A Series of mixtures were prepared by mixing water, fine aggregates (sand) and powder materials (cement and $\mathrm{Al}_{2} \mathrm{O}_{3}$ particles) in a concrete laboratory.The formulation of cementitious matrix was based on a ratio water/cement $(\mathrm{E} / \mathrm{C})$ of 0,4 [8] and an addition of the powder of alumina which varies from 2 to $20 \%$ of the mass of the cement.

\subsection{Raw materials}

\subsubsection{Portland cement}

The cement used in this study is a Portland cement CPJ 45 from the AsmentTemara Company which meets the Moroccan standards NM 100.1.004. The composition and the XRF analysis of the cement is indicated respectively in table 1 and table 2 .

\begin{tabular}{cc}
\hline Composition & $\%$ \\
\hline Clinker & 65 \\
Gypse & 2,5 \\
Calcaire & 32,5 \\
C2S & 23,05 \\
C3S & 47,85 \\
C3A & 5,35 \\
C4AF & 9,10 \\
\hline
\end{tabular}

Tab.1.The CPJ 45 Constituent.

\begin{tabular}{cc|cc}
\hline $\mathrm{SiO} 2$ & 20,64 & $\mathrm{~K} 2 \mathrm{O}$ & 0,67 \\
$\mathrm{~A} 2 \mathrm{O} 3$ & 3,93 & $\mathrm{TiO} 2$ & 0,27 \\
$\mathrm{Fe} 2 \mathrm{O} 3$ & 2,99 & $\mathrm{MnO}$ & 0,07 \\
$\mathrm{CaO}$ & 59,41 & $\mathrm{P} 2 \mathrm{O} 5$ & 0,22 \\
$\mathrm{MgO}$ & 1,40 & $\mathrm{Na} 2 \mathrm{O}$ & 0,02 \\
$\mathrm{SO} 3$ & 2,27 & $\mathrm{SrO}$ & 0,058 \\
\hline
\end{tabular}

Tab.2.The XRF analysis of the CPJ 45 (\%)

\subsubsection{Sand}

The sand used in the cement matrices complies with the NM 10.1.020 (EN 196-1) standard [9]. Characterized by its siliceous morphology, the sand is chemically inert towards the components of the mixture. Based on the previous results [10] which demonstrated, that the use of 0.2 mmsand improves the mechanical resistance of the cementitious matrix. The sand used for the preparation of all formulations has a particle size ranging from 0.08 to1.6 $\mathrm{mm}$ (Table 3 ).

\begin{tabular}{ccc}
\hline Tamis $(\mathrm{mm})$ & $\begin{array}{c}\text { Refus Cumulés } \\
\%\end{array}$ & $\begin{array}{c}\text { Tamisât Cumulés } \\
\%\end{array}$ \\
\hline 1,6 & 0,06 & 99,94 \\
0,8 & 0,22 & 99,78 \\
0,4 & 4,35 & 95,65 \\
0,2 & 95,89 & 4,11 \\
0,08 & 99,72 & 0,28 \\
Fond & 100 & 0 \\
\hline
\end{tabular}

Tab.3.The particle size analysis of sand

\subsubsection{Water}

The used water in this study is tap water with a $\mathrm{pH}$ of 7.38 and an ionic conductivity of $672 \mu$ s.

\subsubsection{Alumina powder}

The $\mathrm{Al}_{2} \mathrm{O}_{3}$ particles constitute a fine, uniform, and smooth powder, without aggregates, with a micrometric size. The alumina used in this study was acquired from a Moroccan branch of industry.

\begin{tabular}{llll}
\hline matériau & $\begin{array}{l}\text { Surface } \\
\text { spécifique } \\
\left(\mathrm{m}^{2} / \mathrm{g}\right)\end{array}$ & $\begin{array}{l}\text { Densité } \\
\left(\mathrm{g} / \mathrm{cm}^{3}\right)\end{array}$ & Purity \\
\hline $\mathrm{Al}_{2} \mathrm{O}_{3}$ & 200 & 0.12 & $>99.8 \%$ \\
\hline
\end{tabular}

Tab.4.Alumina powder characterisation

\subsection{Equipments}

The used equipment to measure the compressive strength is a manual type hydraulic press Carver Model (4350.L) $\mathrm{S} / \mathrm{N}$ (4350-362), it has a capacity that reaches 24000 Pounds.

To mix the components, the apparatus is an automatic mixer, type $3 \mathrm{R}$, this device has a capacity of $5 \mathrm{~L}$, and it ensures an uniform and homogeneous mixture.

The sieving of the sand and the red clay is realized with a column of sieve of $3 \mathrm{R}$ type.

\subsection{X-Ray diffraction analysis}

The Alumina powder was analyzed with a P Analytical diffractometer X PERT POWDER copper anticathode $(\lambda \operatorname{Cuk} \alpha=1.5406 \AA)$. 


\subsection{X-Ray Fluorescence analysis}

$\mathrm{XRF}$ is a non-destructive analytical method for materials. It is a quantitative and qualitative analysis of the elements which are present in the samples. An analysis of the Alumina powder, the cement and the cement matrices was carried out by the S1Turbo SD system.

\subsection{The experimental protocol}

The experimental protocol used in this study to prepare the cementitious matrices is as follows:

- The necessary amounts of cement, sand and Alumina powder are introduced into the bowl and the mixing is carried out dry for $1 \mathrm{~min}$.

- To prevent overflow the required amount of water is added gradually.

- The components are mixed at slow rate for 1 min and at a fast rate for $2 \mathrm{~min}$.

- The cement paste was introduced in cylindrical specimens of $10 \times 5,6 \mathrm{~cm}$ and vibrated for a few seconds.

\subsection{Formulation tests}

The main purpose of this study is to manufacture mortars reinforced by alumina powder to study the effects of Alumina powder addition on the compressibility and physicochemical properties of the cement mortars. For that reason, different formulation tests were done (Table $5)$.

\begin{tabular}{cccc|c}
\hline & $\begin{array}{c}\text { Ciment } \\
\%\end{array}$ & $\begin{array}{c}\text { Sable } \\
\%\end{array}$ & $\begin{array}{c}\text { Eau } \\
\%\end{array}$ & $\begin{array}{c}\text { Addition } \\
\text { d'Alumine } \\
\text { en } \%(*)\end{array}$ \\
\hline Témoin & 57,14 & 20 & 22,85 & 0 \\
\hline Test 1 & 57,14 & 20 & 22,85 & 2 \\
\hline Test 2 & 57,14 & 20 & 22,85 & 4 \\
\hline Test 3 & 57,14 & 20 & 22,85 & 6 \\
\hline Test 4 & 57,14 & 20 & 22,85 & 8 \\
\hline Test 5 & 57,14 & 20 & 22,85 & 10 \\
\hline Test 6 & 57,14 & 20 & 22,85 & 12 \\
\hline Test 7 & 57,14 & 20 & 22,85 & 14 \\
\hline Test 8 & 57,14 & 20 & 22,85 & 16 \\
\hline Test 9 & 57,14 & 20 & 22,85 & 18 \\
\hline Test 10 & 57,14 & 20 & 22,85 & 20 \\
\hline
\end{tabular}

Tab.5.Formulation tests

* The calculation of the percentage of Alumina is adjusted with regard to the mass of the cement.

\section{RESULTS AND DISCUSSION}

\subsection{Particle size distribution of $\mathrm{Al}_{2} \mathrm{O}_{3}$ powder}

The analysis of the $\mathrm{Al}_{2} \mathrm{O}_{3}$ powder particles is shown in figure 1. According to the results, the majority of the particles constituting the Alumina powder have a size of $88 \mu \mathrm{m}$, which satisfy the standards of the use of fillers in the cementitious matrices NF P 18-501 [11]. 4.

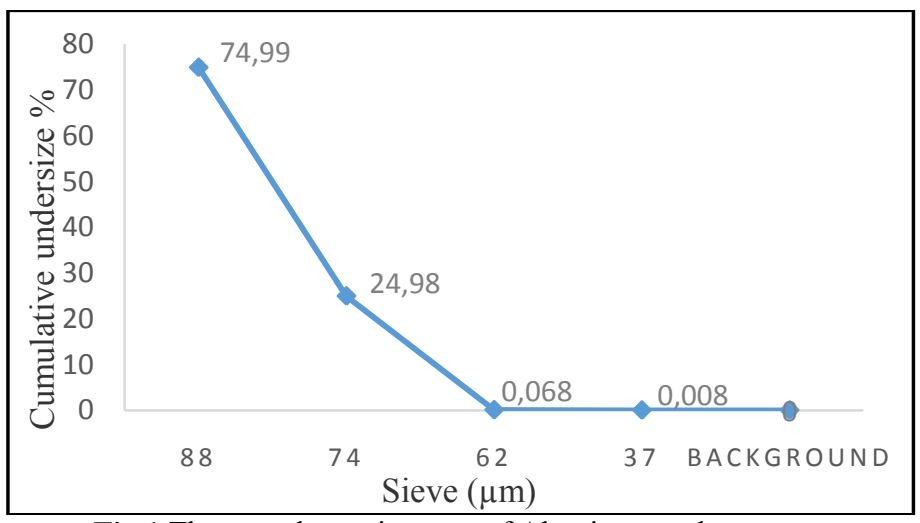

Fig.1.The granulometric curve of Alumina powder

\subsection{Quantitative chemical analysis of $\mathrm{Al}_{2} \mathrm{O}_{3}$}

To determine the chemical composition of the Alumina powder, a XRF analysis was performed (Table 6).

\begin{tabular}{cc}
\hline Oxydes & Alumine \% \\
$\mathrm{Al}_{2} \mathrm{O}_{3}$ & $81,82 \pm 1$ \\
$\mathrm{SiO}_{2}$ & $0,38 \pm 0,17$ \\
$\mathrm{Fe}_{2} \mathrm{O}_{3}$ & $0,070 \pm 0,004$ \\
$\mathrm{CaO}$ & $0,18 \pm 0,03$ \\
$\mathrm{~K}_{2} \mathrm{O}$ & $0,20 \pm 0,02$ \\
$\mathrm{TiO}_{2}$ & $\mathrm{ND}$ \\
$\mathrm{P}_{2} \mathrm{O}_{5}$ & $0,87 \pm 0,04$ \\
\hline Tab.6.X-Ray Fluorescence of $\mathrm{Al}_{2} \mathrm{O}_{3}$
\end{tabular}

\subsection{X-ray diffraction of $\mathrm{Al}_{2} \mathrm{O}_{3}$}

The pattern diffraction (Figure 2) shows that corundum (crystalline form of Aluminum oxide $\mathrm{Al}_{2} \mathrm{O}_{3}$ ) is the major mineral present in Alumina powder sample. 


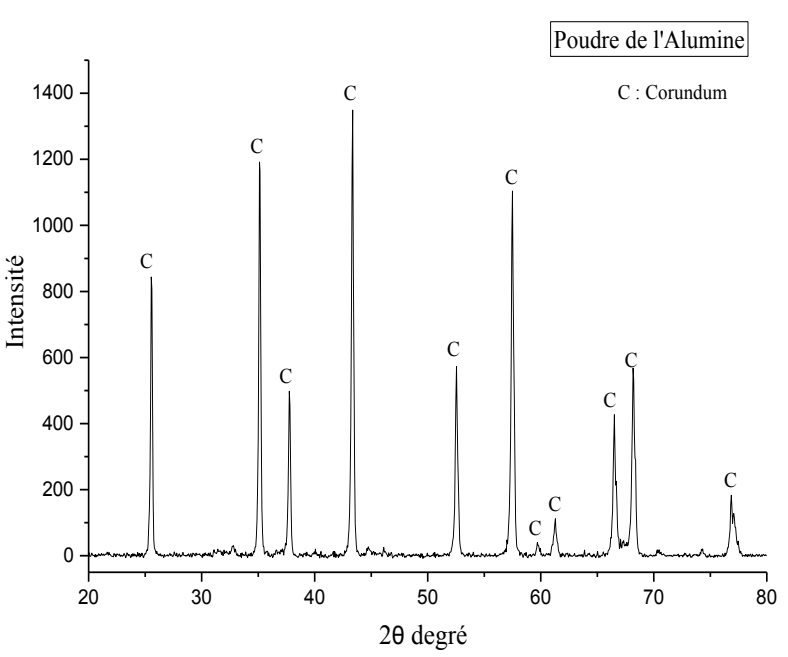

Fig.2 .The diffraction pattern of Alumina powder

\subsection{Compressive strength}

The Compressive strength of mortars incorporating different content of Alumina powder at different curing periods $(7,14,21$ and 28 days) is illustrated in Figure 3. The results of the compressibility are given in $\mathrm{MPa}$ (Mega Pascal).

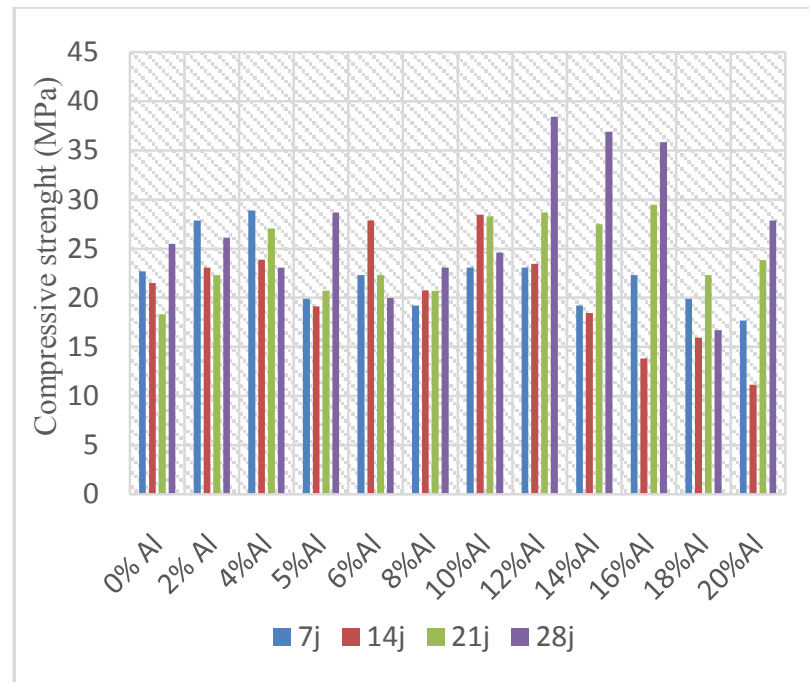

Fig.3.The compressive strength of the cement matrices

According to figure 3, the compressive strength of mortar containing alumina particles was clearly improved. The 28-day compressive strength of matrix was enhanced as much as $51 \%$ by adding $12 \mathrm{wt} \%$ of cement with alumina powder. The compressive strength increased from 25.48 $\mathrm{MPa}$ to $38,43 \mathrm{MPa}$ when the content of $\mathrm{Al}_{2} \mathrm{O}_{3}$ increased from $0 \mathrm{wt} \%$ to $12 \mathrm{wt} \%$. The enhancement of compressive strength of cement matrix containing alumina micro-size particles was probably due to the rapid consuming of calcium hydroxide $\mathrm{Ca}(\mathrm{OH})_{2}$ formed during hydration of Portland cement [12], related to the high reactivity of $\mathrm{Al}_{2} \mathrm{O}_{3}$ particles [13-14].

$$
\mathrm{Ca}(\mathrm{OH})_{2}+\mathrm{Al}_{2} \mathrm{O}_{3} \rightarrow \mathrm{CAH}
$$

Also the Al2O3particles increase the density of the cementitious matrix, and they act as filler which will strengthen the microstructure of the mortar and will reduce the volume of pores in the cement paste [ 15-16 ].. The mechanical properties and frost resistance of matrix containing $\mathrm{Al}_{2} \mathrm{O}_{3}$ particles in compare with normal witness matrix were improved.

The mechanism allowing to improve the physicochemical and mechanical properties of cementitious matrix containing the powder of alumina can be interpreted as follows; If the powder of alumina is uniformly dispersed, at the beginning of the hydration, the crystallization will be controlled by limiting the growth of the crystal That $\mathrm{Ca}(\mathrm{OH})_{2}$..

Moreover, the alumina behaves not only as filler, but also as activators which favorites the reaction pozzolanique, and is going to react with the hydroxide of calcium formed from the hydration of the silicate of calcium [1719]. The rate of pozzolanique reaction is proportional to the available surface quantity for the reaction. consequently, the medium-sized pores in the matrix of cement decrease with the use of particles $\mathrm{Al}_{2} \mathrm{O}_{3}$ (Picture 1) $[20]$.

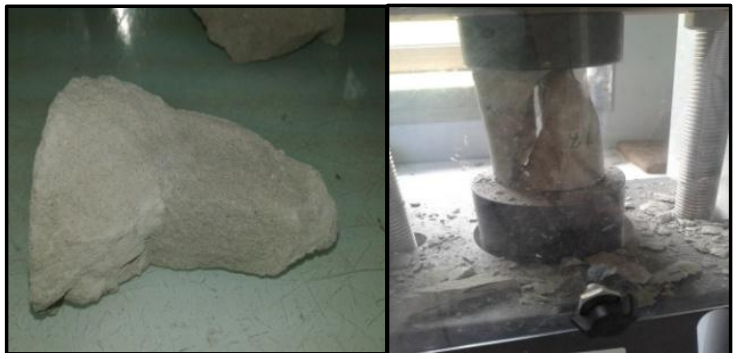

Img.1.Pic.1.cementitious matrix with added $\mathrm{Al}_{2} \mathrm{O}_{3}$

This makes the cementitious matrix with an add of a percentage of Alumina powder that ranges from $12 \%$ to $20 \%$, as an optimum percentage for addition, more homogeneous and compact, that will give the highest compressive strength compared to the cement matrix without $\mathrm{Al}_{2} \mathrm{O}_{3}$.

\subsection{X-ray fluorescence analysis of cementitious matrix}

The x-ray fluorescence analyzes were also performed on the cementitious matrix (Witness, 12\% Alumina, 14\% Alumina) and the results are indicated in table 7

\begin{tabular}{llll}
\hline Oxydes & $\begin{array}{l}\text { Mortier } \\
\text { témoin }\end{array}$ & $\begin{array}{l}\text { Mortier } \\
12 \% \mathrm{Al}\end{array}$ & $\begin{array}{l}\text { Mortier } \\
14 \% \mathrm{Al}\end{array}$ \\
\hline $\mathrm{Al}_{2} \mathrm{O}_{3}$ & 6,63 & 16,30 & 18,45 \\
$\mathrm{SiO}_{2}$ & 14,30 & 12,03 & 11,25 \\
$\mathrm{Fe}_{2} \mathrm{O}_{3}$ & 2,93 & 2,64 & 2,58 \\
$\mathrm{CaO}$ & 57,55 & 52,70 & 50,57
\end{tabular}




\begin{tabular}{llll}
$\mathrm{K}_{2} \mathrm{O}$ & 0,76 & 0,64 & 0,58 \\
$\mathrm{TiO}_{2}$ & 0,14 & 0,13 & 0,14 \\
$\mathrm{P}_{2} \mathrm{O}_{5}$ & 2,21 & 2,04 & 1,95 \\
$\mathrm{MnO}$ & 0,07 & 0,07 & 0,07 \\
\hline
\end{tabular}

Tab.7.XRF analysis of cementitious matrix

Compared to the witness mortar, the XRF analysis showed an increasing of $\mathrm{Al}_{2} \mathrm{O}_{3}$ percentages by the addition of $12 \% \mathrm{Al}$ and $14 \% \mathrm{Al}$ into the cementitious matrix, next to a decreasing in the $\mathrm{CaO}$ content, which will be explained by the pozzolanic reaction that consume more $\mathrm{CaO}$ in the presence of $\mathrm{Al}_{2} \mathrm{O}_{3}$ powder to produce the $\mathrm{CSH}$ and $\mathrm{CAH}$ phases.

\subsection{Analyse par DRX des matrices cimentaires}

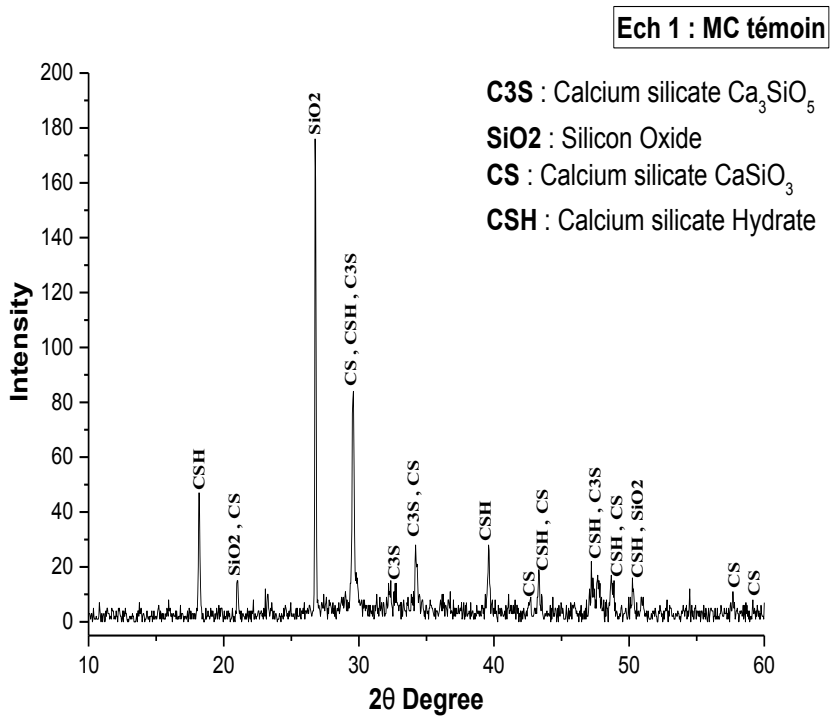

Fig.3. Diffraction pattern of diffraction of matrix without Al.

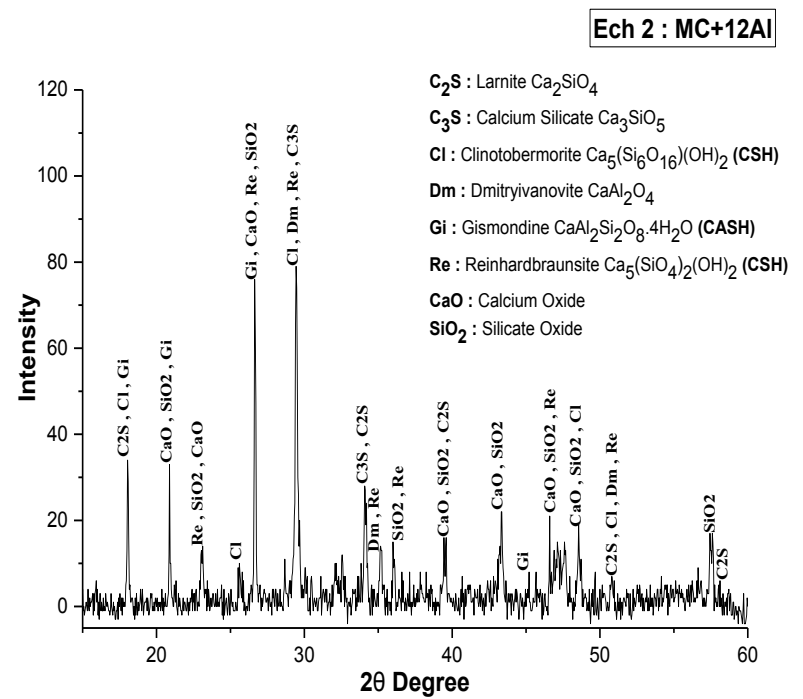

Fig.4.Diffraction pattern of matrix with $12 \% \mathrm{Al}$

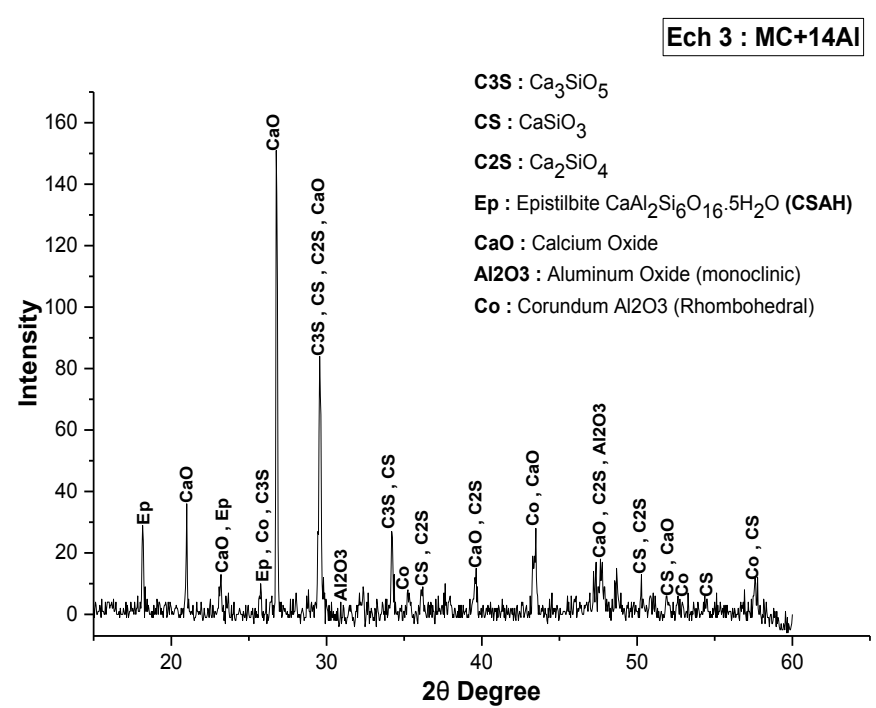

Fig.5.Diffraction patternpattern with $14 \% \mathrm{Al}$

The diffractogram of the matrix without $\mathrm{Al}$ ( fig. 3 ) shows the presence of the phases of silicate of tricalcium, of silicate of calcium hydrated ( C-S-H). These crystalline structures constitute the main product of hydration of the Portlandcement and are mainly responsible for the resistance in the cement-based materials.

Matrix containing $12 \%$ and $14 \%$ of alumina are respectively represented on figures 4 and 5 , these show that that of products of hydration such as the frosts of aluminate some calcium $\mathrm{CAH}$, result of the reaction pozzolanique between $\mathrm{Al} 2 \mathrm{O} 3$ and That $(\mathrm{OH})$ 2, appear. This could strengthen the microstructure of the mortar and reduce the volume of pores in the dough of cement. The introduction of the powder of Alumina in our dough of cement acts on its microstructural properties and consequently strengthens the matrix cimentaire by increasing its compression resistance with regard to the Control mortar[21].

\section{CONCLUSION}

The result of this study showed that the addition of alumina powder in the cement matrices increases the compressive strength at the age of 28 days compared to the control mortar. An improvement can also be noted by adding $12 \%$ to $20 \%$ of the alumina to the ordinary mortar matrix. The addition of $12 \%$ alumina powder increases the compressive strength of the mortar by $51 \%$ compared to the control mortar (without alumina).

This result is explained by the filler effect of the $\mathrm{Al}_{2} \mathrm{O}_{3}$ powder, the behavior of alumina as an activator which promotes the pozzolanic reaction.

Acknowledgments: The authors would like to express their gratitude to the Radioactive Waste Management Unit (UGDR) of the National Center for Energy, Nuclear 
Science and Technology (CNESTEN) of Morocco and the Faculty of Science of Ibn University Tofail, in Kenitra, Morocco, to provide the necessary support for this work, also Pr DIOURI from the Faculty of Sciences of Rabat for his assistance in carrying out the DRX analyzes.

\section{Références}

1. Michael I Ojovan, William E. Lee, An Introduction to Nuclear Waste Immobilisation 2, Newnes, 376, (2013).

2. El Ghailassi T., Système de gestion des déchets radioactifs entreposage des déchets radioactifs et combustible Usé Triga Mark II. Rapport de titularisation, 8-9, (2008).

3. IAEA, Predisposal Management of Radioactive WasteSeries No. GSR Part 5, published Tuesday, 19 May, (2009).

4. International atomic energy agency Vienna IAEAtecdoc-1701, the behaviors of cementitious materials in long term storage and disposal of radioactive waste, 3-20, (2013).

5. D.M. Montgomery., the Optimization of cementbased stabilization/solidification of organiccontaining industrial wastes using organophilic clays,Volume9,Issue 1, 21-34, (February 1991).

6. Behfarnia K., Salemi N., The effects of nano-silica and nano-alumina on frost resistance of normal concrete, Construction and Building Materials 48,580-584, (2013).

7. Sikora P., Horoszczaruk E., Cendrowski K., Mijowska E, The Influence of nano-Fe3O4 on the microstructure and mechanical properties of cementitious composites. NanoscaleResearch Letters11, 182, (2016).

8. El Ghailassi T., AouladBelayachi,A. Bouih, S. Labied, T. Guedira, O. Benali. Mathematical approach for research of new formulation for immobilization of radioactive waste in cementitious matrices, JMES Accepted, (2017).

9. Office national de l'eau potable, Tome 4 Génie Civil 2009-11-16, Morocco, 2-3, (2009).

10. Faiz Z., Fakhi S., Bouih A., Idrissi A., Mouldouira M., J. Mater. Environ. Sci. 3 (6), 1129-1136, (2012).

11. Pineau F., Corcos J., Pitiot A, Spécification technique pour les colis de déchets conditionnés dans une enveloppe durable confinante, à base de liants hydrauliques, destinés au stockage sur un site de surface. ANDRA-ACO-SP-ASQC--95-064/A,1-30, (1995).

12. Herzog A., Mitchell J.K, Reactions accompanying the stabilization of clay with cement. Highw. Res. Board Rec. 36, 146-171, (1963).
13. KiachehrBehfarnia, NiloofarSalemi., The effects of nano-silica and nano-alumina on frost resistance of normal concrete, Construction and Building Materials 48, 580-584, (2013).

14. Prusinski R., Bhattacharja S, Effectiveness of Portland cement and Lime in Stabilizing Clay Soils.,TRANSPORTATION RESEARCH RECORD 1652, 215-227,(1999).

15. Li H, Xiao H, Yuan J, Ou J., Microstructure of cementmortarwith nano-particles.,

Composites Part B, 35(2), 185-9, (2003).

16. Sneff L, Labrincha JA, Ferreira VM, Hotza D, Repette WL., Effect of nano-silica on rheology and fresh properties of cement pastes and mortars., Constr Build Mater,23(7),2487-91,(2009).

17. A. Nazari, S. Riahi, Abrasion resistance of concrete containing $\mathrm{SiO} 2$ and $\mathrm{Al} 2 \mathrm{O} 3$ nanoparticles in different curing media, Procedia Eng. 43, 29392946, (2011).

18. Li $\mathrm{H}$, Zhang $\mathrm{M}$, Ou J. Abrasion resistance of concrete containing nano-particles for pavement.,260(11-12):1262-6,(2006).

19. Ali N, Shadi R, Shirin R, Fatemeh S, Khademno A. Influence of $\mathrm{Al} 2 \mathrm{O} 3$ nanoparticles on the compressive strength and workability of blended concrete. J Am Sci; 6(5), 6-9, (2010).

20. M. R. Arefi, M. R. Javeri, E. Mollaahmadi., To study the effect of adding $\mathrm{Al} 2 \mathrm{O} 3$ nanoparticles on the mechanical properties and microstructure of cement mortar, Life Science Journal,8(4), (2011).

21. S0 Mukherjee, S. Barbhuiya, H.Nikraz. Effects of nano-A12O3 on early-age microstructural properties of cement paste, research gat, (February 2014). 